\title{
THE IDENTIFICATION OF BACTERIAL SYMBIONT'S OF THE LARVAE ORYCTES RHINOCEROS L. AND THE ROLE OF THE BACTERIA IN COMPOSTING PROCESS
}

\author{
Octanina Sari Sijabat $^{*}$, Marheni ${ }^{1}$, Darma Bakti ${ }^{1}$ \\ ${ }^{1}$ Faculty of Agriculture, University of North Sumatra, Medan, Indonesia \\ *Corresponding Author: octanina366@gmail.com
}

\begin{abstract}
Oryctes rhinoceros L. has symbioses with micro organisms in their hind guts which further break down plant material consumed by beetle. The aim of this research is to determine the identification of the existence of the bacterial species in the hind gut larvae of the symbiotic bacteria using biochemical test and analysis based on $16 S$ rRNA. The result of this research indicate that there were two different bacterials: Bacillus siamensis and Bacillus stratosphericus found. The bacteria was used for starting the composting and more specifically, the Bacillus siamensis can speed up composting with the end result at $C / N 13.16$.
\end{abstract}

Keywords: Larvae O. rhinoceros L, Bacterial Symbionts, $16 \mathrm{~S}$ rDNA, Composting

\section{INTRODUCTION}

Empty bunches of palm and palm stems are a dynamic breeding medium, due to decomposition and degradation process. Empty bunches and palm stems into place to lay eggs and live media larvae and pupae. Decomposition process that occurs on a media indicates the physical and chemical changes of the media. The phenol and phenyl phenol compounds of the decomposition process O. rhinoceros L. (Renou et al., 1998).

The existence of symbiotic relationships between bacteria and insects varies from mutualistic and pathogenic. Intracellular symbionts in insects are classified as either primary or secondary endosymbi. The genus of Oryctes is considered a very harmful pest. The presence of an insect-bacterial endosymbionts association is present in the genus Oryctes (Elsayed et al, 2015).

Digestion and absorption of food takes place in the digestive tract divided into three parts: the intestine, the middle intestine, the intestine, the digestion of the food takes place in the intestine, in this section there are a number of bacterial symbionts that release cellulase enzymes to decompose cellulose (Solihat, 2006).

Bacteria that play a role in the composting process is very diverse, the bacteria that play a role in the degradation of cellulose is a symbiotic bacteria that is not only played by cellulolitic bacteria but also played by non-cellulolytic bacteria that help in the process of degradation of compost material. Research on the presence of symbiotic bacteria in the digestive tract of larvae of O. rhinoceros $\mathrm{L}$ derived from the pile of organic material empty bunches of palm oil and palm stem and its utilization as a composting starter has not been done, therefore the purpose of this study to identify bacteria in the digestive tract of larvae and bacteria utilization symbionts for composting.

\section{MATERIALS AND METHODS}

The materials used in this research are Larva $O$. rhinoceros $\mathrm{L}$. instar 3, The materials used in this research are: Sodium agar, sterile aquadest, alcohol, spiritus. For Gram staining crystal violet dye, lugol, $96 \%$ alcohol, $70 \%$, safranin, Biochemical Test materials, litter, cow dung. Fruits, coconut water is used to make local microorganisms (MOL).

\subsection{Bacterial isolation}

Several instar 3 larvae were sterilized on the outside, then the intestine part was removed by sterile scissors, taken from the back of the intestine and weighed as much as 10gram and then added with $90 \mathrm{ml}$ of sterile and homogenized aquadest (Li et al., 2003).

Then made several dilutions grown on the media using a spread system and then incubated for 18 hours at $37^{\circ} \mathrm{C}$. The bacterial colonies that grow later are purified (Wenzel et al., 2002).

From Gram staining, the shape and color of bacterial cells were observed under a microscope with magnification 1000 times. Gram-negative bacteria are red and gram-positive bacteria are blue. 
Biochemical Test Bacteria were carried out with biochemical media to be used which had been incubated for 24-48 hours with $37^{\circ} \mathrm{C}$ incubator temperature using starch medium (SA) Positive test if there was a clear zone in the colony after iodine drop. Gelatin Hydrolysis Test Take the semi-solid gelatin medium in the test tube, Test positive if the medium remains liquid after it is inserted into the refrigerator. Test Citrate Take SCA media then scratch the bacterial inoculum on the media with a twisted needle. A positive test occurs if there is a change of color on the green medium to blue. Hydrogen Sulfide Test Prepare a sloping medium TSIA scratch the inoculum on the surface of the media using a twisted needle, Observe the cracks that occur on the media and the presence of black deposits. The motility test was conducted using the media SIM in the test tube Observe the type of movement of bacteria. Test Catalase Prepare a wet glacial object and then inoculate one loop used on the glass and observe the changes. Observe the presence of air bubbles.

\subsection{Composting}

The bacteria that have been identified from the digestive tract are then used as composting starters to accelerate the maturity of the compost, because the genus of basilus can produce lipase and cellulose enzymes that can be utilized as microbial inoculum.

The composting test is done in the laboratory using a bucket. Prepared artificial molasses made from fruits (papaya, banana, pineapple, coconut water) then blended and left for 2 weeks for the fermentation, the fermentation is declared successfully marked by the foam and brown. After that applied or sprayed on cow dung stirred and added with litter. After a week later the bacterial starter derived from the larvae was sprayed again on the surface of cow dung and litter that had been applied with mole. Observed the scale of the maturity of the composting.

\section{RESULTS AND DISCUSSION}

The bacteria derived from basillus genus and advanced test using 16S-rRNA with sequencing result showed the following nucleotide composition: TTTTGGTGGTTTGCGGCATGCTGATCGCGATTACTAGCGATTCCAGCTTCACGCAGTCGAGTTGCAGAC TGCGATCCGAACTGAGAACAGATTTGTGGGATTGGCTTAACCTCGCGGTTTCGCTGCCCTTTGTTCTGC CCATTGTAGCACGTGTGTAGCCCAGGTCATAAGGGGCATGATGATTTGACGTCATCCCCACCTTCCTCC GGTTTGTCACCGGCAGTCACCTTAGAGTGCCCAACTGAATGCTGGCAACTAAGATCAAGGGTTGCGCT CGTTGCGGGACTTAACCCAACATCTCACGACACGAGCTGACGACAACCATGCACCACCTGTCACTCTG CCCCCGAAGGGGACGTCCTATCTCTAGGATTGTCAGAGGATGTCAAGACCTGGTAAGGTTCTTCGCGT TGCTTCGAATTAAACCACATGCTCCACCGCTTGTGCGGGCCCCCGTCAATTCCTTTGAGTTTCAGTCTT GCGACCGTACTCCCCAGGCGGAGTGCTTAATGCGTTAGCTGCAGCACTAAGGGGCGGAAACCCCCTAA CACTTAGCACTCATCGTTTACGGCGTGGACTACCAGGGTATCTAATCCTGTTCGCTCCCCACGCTTTCG CTCCTCAGCGTCAGTTACAGACCAGAGAGTCGCCTTCGCCACTGGTGTTCCTCCACATCTCTACGCATT TCACCGCTACACGTGGAATTCCACTCTCCTCTTCTGCACTCAAGTTCCCCAGTTTCCAATGACCCTCCC CGGTTGAGCCGGGGGCTTTCACATCAGACTTAAGAAACCGCCTGCGAGCCCTTTACGCCCAATAATTC CGGACAACGCTTGCCACCTACGTATTACCGGCGGCTGCTGGGCACGTAGTTTAGCCGTGGCTTTTCTGG TTAGGGTACCGTCCAAGGTGCCGCCCCTATTTGAAACGGCACTTGGTTCTTCCCTTAACAACAGAAGCT TTTACGAATCCGAAAAACCTTTCATCACTTCACGCGGGCGTTTGCTCCCGTCAAAACTTTCCGTCCATT GGCGGAAAAATTCCCTAACTGCCGGCCTCCCCGTAAGGAATTCTTGGGCCCGGGGTCTCAAGTCCCCA GTGTTGGGCCGAATCACCCCTCTCCAAGGTCCGGCTAACCCCATCCGTCCCCCTTGGGTGGAACCCGTT TACCCTCCACCCAACTAAGACTAAAGGGCCCCCCCGGGGTTCCATTCTGTAAAAGTGGGTAAGCCCGA AAGCCACCATTTTTAATGGTCTGGAAACCATTGGCGGGTTTCTAACCAAACCATTCCCGGGTATTTAAG CCCCCGGGTTTTTCCCGGGAAATTTTATCCCCAAGACCTTAACAAGGGGGAGGGTTAACCCCCCCGGG TGGTATAACCCAACCCGGGCCCCCCCCCGCTTAAACATAAACGGGGGAACAAAAAAGTTCCCCACTAT TTGTGCCCGCTTCCCCAATTAGGAAAGGGGAGGTTTTAAAGGGGTCCTGTGGCACACTAGGATATAAA TAAGTATTAAAAGGATATATTAA

The sequence of sequenced nucleotides is shown in Bacillus siamensis species found in larvae that live in rotted palm stems. The nucleotide arrangement of the isolated stem larval symptom bacteria was then identified using the BLAST program at www.ncbi.com and obtained 14 isolates having similarity nucleotide arrangement with 98 to $99 \%$ similarity.

It can be seen in the similarity table between a single species of Basilius siamensis with a species that has proximity to the nucleotide arrangement with other bacilli species. The similarity in the table is the distance between the proximity of the nucleotide arrangement and still in a kinship or also still in a cluster that can be seen from the value listed in table 1 . Then with phylogenic trees showing the fenetic familial in Figure 1. 


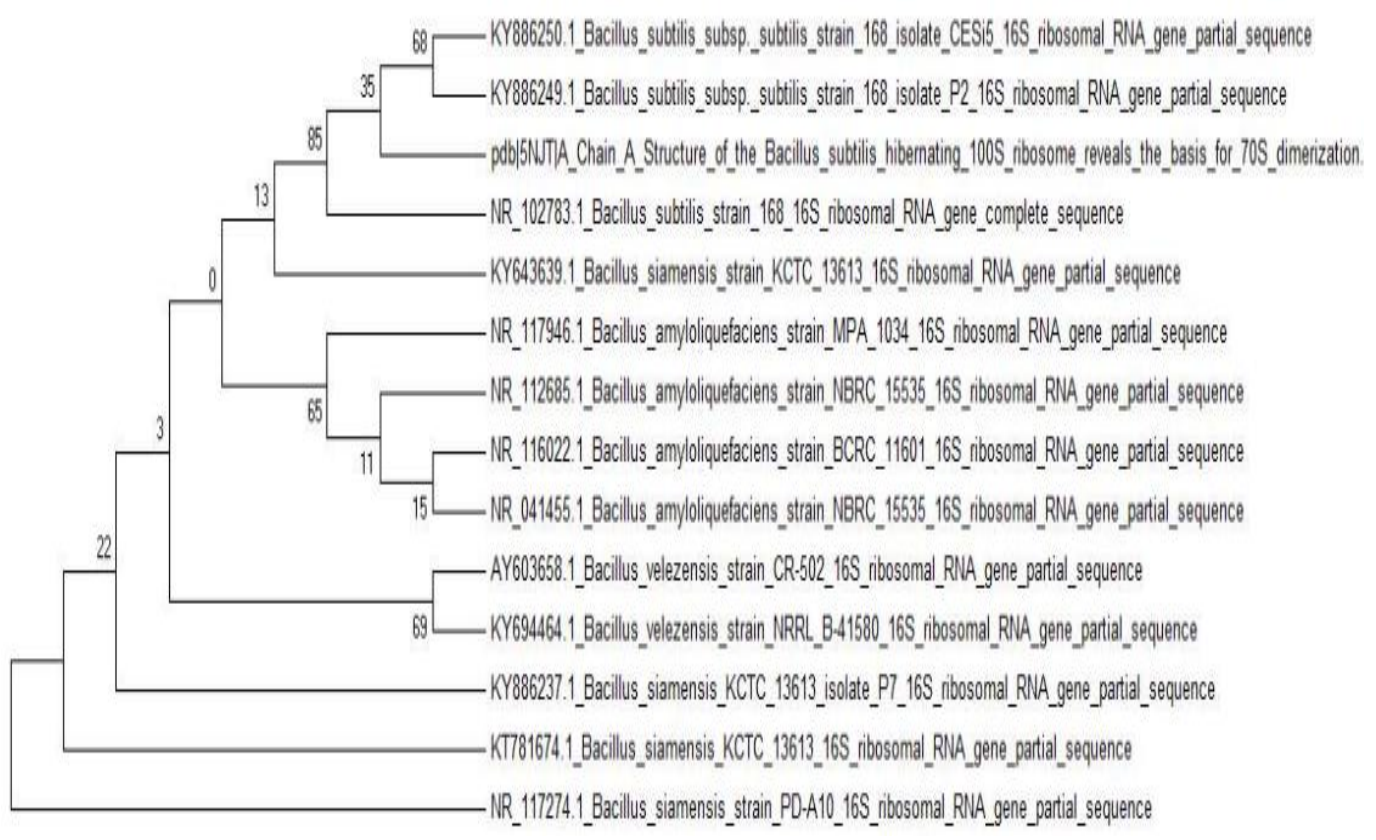

Figure 1. Phylogenic tree of the larvae of stem larval genes, with CLUSTAL W and 1000 replications.

This phylogenic tree can explain the closeness of the kinship between species that can be seen that produces 2 clusters and species Basilus Siamensis has proximity to B. Veleziensis. Identification of bacteria from tankos using this 16S rRNA to determine the order of its nucleotides because all species have different arrangement or sequence of each nucleotid chain (Timin, Guanin, Adenin, Citosin). While the result of scuensing species of larval symbiont bacteria that live in empty fruit bunches is Bacillus stratosphericus with nucleotide arrangement as follows:

AACCCAAAATTCCGCTTGCTGATCGCGATTACTAGCGATTCCAGCTTCACGCAGTCGAGTTGCAGACT GCGATCCGAACTGAGAACAGATTTGTGGGATTGGCTAAACCTTGCGGTCTCGCAGCCCTTTGTTCTGTC CATTGTAGCACGTGTGTAGCCCAGGTCATAAGGGGCATGATGATTTGACGTCATCCCCACCTTCCTCCG GTTTGTCACCGGCAGTCACCTTAGAGTGCCCAACTGAATGCTGGCAACTAAGATCAAGGGTTGCGCTC GTTGCGGGACTTAACCCAACATCTCACGACACGAGCTGACGACAACCATGCACCACCTGTCACTCTGT CCCCGAAGGGAAAGCCCTATCTCTAGGGTTGTCAGAGGATGTCAAGACCTGGTAAGGTTCTTCGCGTT GCTTCGAATTAAACCACATGCTCCACCGCTTGTGCGGGCCCCCGTCAATTCCTTTGAGTTTCAGTCTTG CGACCGTACTCCCCAGGCGGAGTGCTTAATGCGTTAGCTGCAGCACTAAGGGGCGGAAACCCCCTAAC ACTTAGCACTCATCGTTTACGGCGTGGACTACCAGGGTATCTAATCCTGTTCGCTCCCCACGCTTTCGC TCCTCAGCGTCAGTTACAGACCAGAGAGTCGCCTTCGCCACTGGTGTTCCTCCACATCTCTACGCATTT CACCGCTACACGTGGAATTCCACTCTCCTCTTCTGCACTCAAGTTTCCCAGTTTCCAATGACCCTCCCC GGTTGAGCCGGGGGCTTTCACATCAGACTTAAGAAACCGCCTGCGAGCCCTTTACGCCCAATAATTCC GGACAACGCTTGCCACCTACGTATTACCGCGGCTGCTGGCACGTAGTTAGCCGTGGCTTTCTGGTTAG GTACCGTCAAGGTGCAAGCAGTTACTCTTGCACTTGTTCTTCCCTAACAACAGAGCTTTACGATCCGAA AACCTTCATCACTCACGCGGCGTTGCTCCGTCAGACTTTCGTCCATTGCGGAAGATTCCCTACTGCTGC CTCCCGTAGGAGTCTGGGCCGTGTCTCAGTCCCAGTGTGGCCGATCACCCTCTCAGGTCGGCTACGCAT CGTCGCCTTGGTAAGCCGTTACCTCACCAACTAGCTAATGGGCCCCCGGGTCCATCTGTAAATGACAA CCCAAAACCGTCTTTTCATCCTTGAAACCAGGGGGTTCAAGGGAATTATCCGGGATTTAACTCCCGGTT TCCCGGAATTATCCCAGGTCTTACAGGGCAGGTTACCCACCGTGTTAACCACCCCGTTGCCGCTTAAA ATCCGGGAAGAAGATCCCTCTTTGCCCCCCAGGTGGGGGGTGTGTGTTGCTTGACTTGGGGAAACCCC $\mathrm{GC}$

The nucleotide arrangement of bacterial isolates of the stem larval symptom obtained was then identified using the BLAST program at www.ncbi.com and 18 isolates were found to have similar nucleotide sequences with 98 to $99 \%$ similarity. 
Then it can also be clarified with a phylogenic tree that can be seen clearly in proximity (Figure 2).

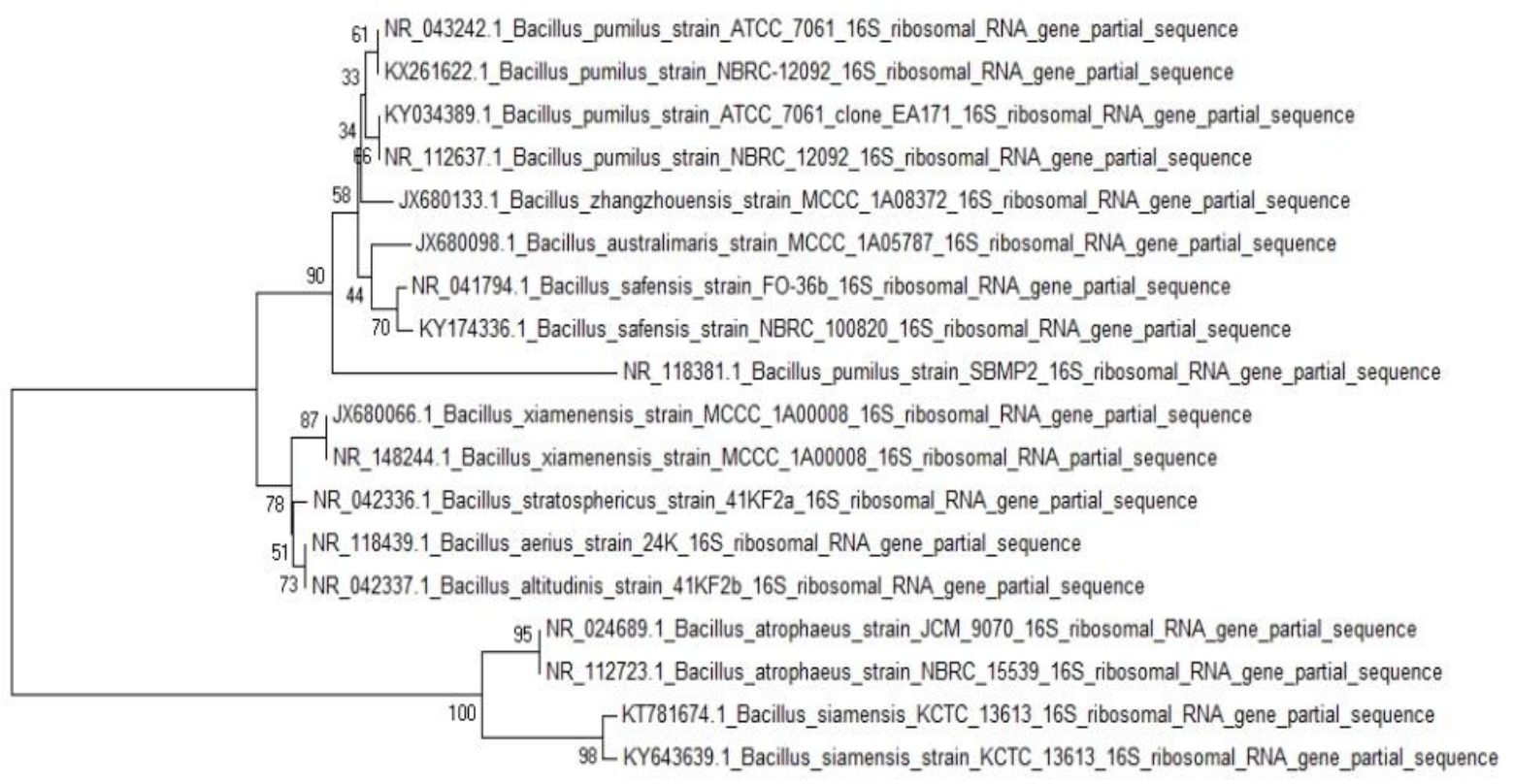

$\longmapsto 0.002$

Figure 2. Phylogenic trees of the empty bunch limb symbionment symbion genes, with CLUSTAL W and 1000 replicates and GenBank.

The gastrointestinal bacteria have mutual relations with their host, which is utilizing host as their place of life. The benefit to host is that bacteria feed on waste or use waste materials, many bacteria living in the intestine can synthesize vitamins, secrete enzymes, and aid digestion of nutrients, and the presence of these bacteria tends to suppress the growth of pathogenic bacteria that can protect host against disease and stimulate immune function its host(Pelczar and Chan, 1986).

From the test results obtained bacteria derived from the genus Bacillus from different species that become the larval symbionts, According to Holt et al., (1994) Bacillus sp. has gram positive properties and is usually motile by peritrichous flagellum. Endospores are oval, sometimes round or cylindrical and highly resistant to unfavorable conditions. Bacteria are not more than one spore per cell and in open air conditions bacterial sporulation cannot stand. This bacterium is aerobic or facultative anaerobic. The ability of bacterial physiology varies, very sensitive to heat, $\mathrm{pH}$ and salinity, kemoorganotroph with fermentation or respiratory metabolism. They are usually catalase and oxidase positive, are widespread in a variety of habitats and are pathogenic to vertebrates or invertebrates. B. siamensis is a bacterium derived from gram positive, facultatif anaerobic and rod-shaped motile. Colonies on cream colored white media. Grows at $37^{\circ} \mathrm{C}$ with pH 6-7 (Sumpavapol et al., 2010).

According to research by Chen et al (2016) Bacillus siamensis is a biocontrol bacteria that produces potential lipopeptides and can reduce the use of pesticides in farmland to control Fusarium oxysporum fungi. Bacillus stratosphericus can be found at altitudes in the stratosphere not limited to the atmosphere and can be found in various environments due to the atmospheric cycle and able to survive in unfavorable conditions, allowing it to colonize and adapt to varying environments.

B. stratosphericus resistance in poor condition includes resistance to UV radiation and tolerance to halo where up to $17.5 \% \mathrm{NaCl}$ is not damaged in cells. It can grow at temperatures between $8^{\circ} \mathrm{C}$ and $37{ }^{\circ} \mathrm{C}$, and at $\mathrm{pH} 6-10$ Furthermore, while certain heavy metals at high concentrations are generally toxic in most organisms $B$. stratosphericus is highly tolerant of $\mathrm{Fe}, \mathrm{Co}, \mathrm{Ni}$, and $\mathrm{Cu}$ ions, and is quite tolerant of $\mathrm{Cd}$ and $\mathrm{Zn}$ ions (Shivaji et al., 2006)

\subsection{Composting}

Changes in temperature and $\mathrm{pH}$ during composting occur as a result of microbial metabolism activity. The metabolism process generates heat so that in the composting will occur temperature rise. The rise in temperature is due to the ongoing activity of microbial metabolism. The bacterial starter is inserted when the compost has reached thermophilic temperature. From the results of the study it can be seen that mixing of MOL and addition of bacteria 
starter of Bacillus siamensis and Bacillus stratosphericus added at the end of the first week have an effect on the speed of maturity of compost, from the observation from the first day until the 30th day it looks physically change the material using mole and starter faster matured when compared to composting without using a starter (18 Days). The addition of this starter fits the genus of bacteria including thermophilic. In the composting process there are 3 different stages with temperature, namely: mesophilic, thermophilic and cooling stage. In the early stages of the mesophilic the process temperature will rise from the ambient temperature, continuously increasing to the thermophilic stage, wherein the microorganisms will be replaced by thermopilic bacteria. Bacillus genus bacteria belong to mesophilic and thermophilic bacteria with temperature range $25-60^{\circ} \mathrm{C}$ (Holt, 1994).

Bacillus's initial activity produces hydrolase enzymes such as amylase, protease, lipase, gelatinase, cellulase. The quality of the litter also affects the activity of soil microorganisms and fauna. The better the quality of the litter, the release of nutrients by microorganisms to the soil more easily. The litter compounds are decomposed and mineralized so as to provide essential elements for the growth of microorganisms. At the beginning of composting the texture of the compost material is still visible in the form of dry litter with light brown with low humidity level due to rapid evaporation. After several stirring, gradually the texture of the compost material turns into more crumb because it has started to occur the decomposition process by microbes so that the material is composted dark brown color and gradually become blackish brown. Polyphenol compounds produced in the process of composting lignocellulose compounds into quinone. The quinone further reacts with the amino compound to form a dark (black) fulvik acid. One indication of the level of compost maturity is by changing the color to a darkish brown soil.

From observation of the first day until the 30th day can be seen the color changes of materials used, litter yellowish and cow dung that is still wet with the addition of MOL at the beginning that has been prepared before the mixture of the compost material get the bacteria needed. At the beginning of the composting process is a type of bacteria derived from the mesophyll group, and at the end of the first week done the addition of starter bacteria for the maturation of the compost can be faster again with the addition of bacteria derived from thermophilic groups namely Basillus siamensis and Basillus stratosphericus. It can be seen from the visual observation that the use of Basillus makes the composting process more quickly mature from the physical criteria that can be seen and has been tested $\mathrm{C}$ / $\mathrm{N}$ ratio, when compared to compos that only use MOL looks more wet and texture more rough on observation and maturation longer. In the composting treatment using local microorganisms from visual observation of litter mixed with cow dung on the final observation it looks rough, the brown color and the compost have smelled like soil.

Table 3. C/N

\begin{tabular}{|l|r|}
\hline Treatment & $\mathrm{C} / \mathrm{N}$ \\
\hline MOL (30 days) & 10.33 \\
\hline MOL + B. stratosphericus (18 days) & 7.65 \\
\hline MOL + B. siamensis (18 days) & 13.16 \\
\hline & \\
\hline
\end{tabular}
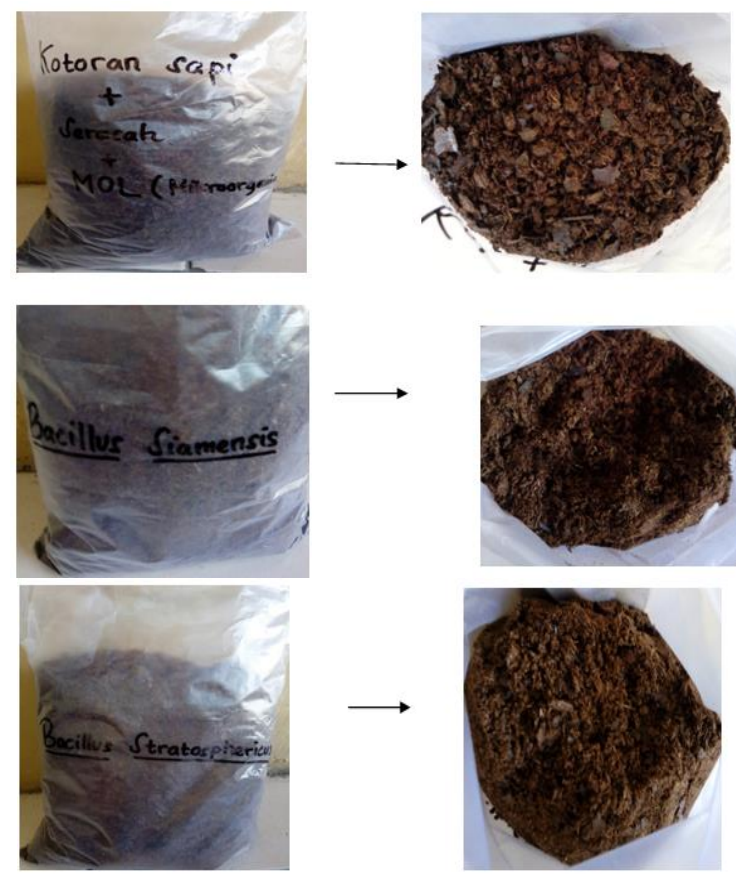
In the composting treatment with the addition of Bacteria B. stratosphericus from visual observation of chopped is more subtle blackish brown and smelling the soil. Likewise with composting with the addition of local microorganisms and bacteria $B$. siamensis not much different physical condition with $B$. stratosphericus.

\section{CONCLUSION}

From the results of identification of the larvae of the larvae $O$. rhinoceros L bacteria were obtained different species of bacteria in one genus, namely Basillus Siamensis from palm stem and Basillus stratosphericus from empty palm bunches. The use of bacterial starter from the genus Basillus can accelerate the maturity of the composting applied at the end of the first week.

\section{REFERENCES}

Elsayed.W and Reda. 2015. Diversity and phylogenetic analysis of endosymbiotic bacteria of the date palm root borer Oryctes agamemnon (Coleoptera: Scarabaeidae). BMC Microbiology201515:88DOI: 10.1186/s12866015-0422-8@.

Chen, Q., Liu,W., Che.,Liu,G,.Gong.,Guan. 2016. Anti Fungal Lipopetides Produced by Bacillus Siamensis FJAT28592. Journal of Agricultural Biotechnology. DOI : 10.3969/J.ISSN. 1674-7968.

Holt, J.G., Krieg, N.R., Sneath, P.H.A., Staley, J.T. dan Williams, S.T. (1994). Bergey's Manual of Determinative Bacteriology. 9th ed. Williams and Wilkins, Maryland.

Li L, J. Frohlich, P. Pfeiffer and H. Konig, 2003. Termite gut symbiotic archaezoa are becoming living metabolic fossils. Eukaryotic Cell, 2(5): 1091-1098.

Pelczar, M. J. Jr. and Chan, E. C. S. 1986. Dasar mikrobiologi.(diterjemahkan dari bahasa Inggris oleh Hadioetomo, R.S., T. Imas, S.S. Tjitrosomo \& S.L. Angka). Volume ke-1,2. UI Press, Jakarta.

Renou, M.D. Tauban and J.P. Morin. 1998. Structur and function of antenal pore plate Sensillia of Oryctes rhinoceros. International Journal of Insect Morphology and Embryology. 27:227-233

Shivaji, S., Chaturvedi, P., Suresh, K., Reddy, G.S., Dutt, C.B.,Wainwright, M., Narlikar, J.V. and Bhargava, P.M. (2006) Bacillus aerius sp. nov., Bacillus aerophilus sp. nov., Bacillus stratosphericus sp. nov. and Bacillus altitudinis sp. nov., isolated from cryogenic tubes used for collecting air samples from high altitudes. Int J Syst Evol Microbiol 56, 1465-1473.

Solihat, A.S. 2006. Kemampuan Isolat bakteri rayap mencerna pakan sumber serat dalam kondisi rumen. Fakultas Peternakan. IPB. Bogor.

Sumpavapol,P.,L.Tongyonk,S.,Tanasupawa, Nipa, C.,P, Luxananil and Wonnop. 2010. Bacillus siamensis sp.nov., isolated from salted crab in Thailand. International journal of Systematic and Evolutionary Microbiology. 60, 2364-2370.

Wenzel M, I. Schonig, M. Berchtold, P. Kampfer and H. Konig, 2002. Aerobic and facultatively anaerobic,cellulolytic bacteria from the gut of the termite Zootermopsis angusticollis. Journal of Applied Microbiology 92: 32-40 